Universität
Basel

Wakultät

ww $\mid \mathrm{Z}$

\title{
On the Credibility of the Euro/Swiss Franc Floor: A Financial Market Perspective
}

Universität Basel

WWZ

Peter Merian-Weg 6

4052 Basel, Switzerland

wwz.unibas.ch
Corresponding Authors:

Heinz Zimmermann

Tel. +41(0)612673316

heinz.zimmermann@unibas.ch 


\title{
On the Credibility of the Euro/Swiss Franc Floor: A Financial Market Perspective
}

\author{
Markus Hertrich $^{\mathrm{a}}$, Heinz Zimmermann ${ }^{\mathrm{b}}$ \\ ${ }^{a}$ Department of Finance, University of Basel, Peter Merian-Weg 6, 4052 Basel, Switzerland. \\ Email: markus.hertrich@unibas.ch \\ ${ }^{b}$ Department of Finance, University of Basel, Peter Merian-Weg 6, 4052 Basel, Switzerland. \\ Email: heinz.zimmermann@unibas.ch
}

\begin{abstract}
The sheer existence of EUR/CHF put options with strike prices below the EUR/CHF 1.20 floor, trading at non-zero cost, challenged the full credibility of the Swiss National Bank (SNB) in enforcing the lower barrier implemented in September 6, 2011 and abandoned on January 15, 2015. We estimate the risk-neutral break probabilities of a realignment of the floor from market prices of put options, using an extension of the Veestraeten option pricing model which assumes that the underlying security price exhibits a lower barrier. We estimate probabilities considerably different from zero, even when the exchange rate traded far above the EUR/CHF 1.20 floor. We observe a drastic increase in the break-probabilities after August 2014, reaching a level of nearly $50 \%$. The credibility of the SNB in maintaining the floor, as seen from the option market, was thus substantially lower than publicly claimed.
\end{abstract}

Keywords: currency options, central banking, credibility, Euro/Swiss franc floor, Vanna-Volga method, barrier

JEL Classification: E42, E58, F31, G13

\footnotetext{
The first and second version of this paper were written in 2013 and 2014, when the EUR/CHF exchange rate floor was effective. During the process of updating the study, in January 2015, the Swiss National Bank abandoned the floor. The present version of the paper not only includes the updated results, but made it necessary to adjust the wording concerning the "credibility" of the floor. Financial support was provided by the Fördergesellschaft of the WWZ, which is gratefully acknowledged. The comments of Martin Andreasen, Axel Kind, Yvan Lengwiler, Christian Kleiber and Evert Wipplinger were very helpful in improving the paper. A previous version of this paper was presented at the 7th CFE-ERCIM Conference at the London School of Economics in 2013.
} 


\section{Introduction}

This paper uses put option prices to empirically analyze the credibility of the EUR/CHF exchange rate floor maintained by the Swiss National Bank (SNB) from September 6, 2011 to January 15, 2015, when the floor was unexpectedly abandoned, as most market observers claimed. The SNB got never tired to insist that it was willing to buy an unlimited amount of Euros to maintain the floor. But the currency options market told a different story: the sheer existence of EUR/CHF put options with strike prices below the EUR/CHF 1.20 floor $^{1}$ trading at positive prices throughout the time period implies that financial market participants questioned the SNB's credibility to enforce this rate. But how strong were these concerns?

We estimate implied risk-neutral probabilities that the exchange rate falls below the EUR/CHF 1.20 floor (called "break" probability in this paper) within one, 3, and 12 months; we use an extension of the option pricing model of Veestraeten (2008), respectively Hertrich and Veestraeten (2013), which extends the Black-Scholes model by assuming an exchange rate that follows a geometric Brownian motion with a reflecting barrier. ${ }^{2}$ In our context, this model allows for a realignment of the prevailing floor to a lower level, i.e. in the model it is assumed that options are priced with a credible reflecting exchange rate barrier below the current floor, specifically, below the exercise prices for which positive put option prices are observed in the market. This means that some investors anticipate a realignment of the floor with non-zero probability. ${ }^{3}$ Furthermore, the difference between the implied and the current exchange rate can be used as a direct measure of the credibility of the Swiss exchange rate

\footnotetext{
${ }^{1}$ Although we analyze the exchange rate from a CHF perspective in this paper, i.e., the number of units of Swiss francs needed to buy one Euro or a floor of 1.20 Swiss francs per Euro, respectively, the exchange rate is referred to as "EUR/CHF" in the body of the text, following the foreign exchange market convention (see Reiswich and Wystup (2010), among others).

${ }^{2}$ The same assumption has previously been used by Gerber and Pafumi (2000) and Ko et al. (2010) for the dynamics of an investment fund.

${ }^{3}$ In the retrospective, given the complete abandonment of the floor in January 2015, this assumption does not seem to be adequate, but this should not be relevant from an ex-ante perspective. In particular, other alternatives to a removal or a realignment of the floor were discussed as well, most notably a pegging of the Swiss franc to a currency basket. See e.g. Bernholz (2015).
} 
policy vis-a-vis the Euro.

The subject of this paper is closely related to a study by Jermann (2015). The underlying economic model is however different: the (unobservable) exchange rate upon which options are priced represents the expected value over two regimes of next period's exchange rate, one with a minimum floor policy and one without. Jermann's model therefore allows for a positive probability that the SNB terminates its monetary regime before the options expire. This introduces an option-like payoff profile into the exchange rate and can be priced by a compound-option style model. ${ }^{4}$ Although the models differ, it is interesting to compare the implications of the empirical findings with respect to the credibility of the SNB's exchange rate policy.

Notice that option-implied break-probabilities are, without further assumptions, riskneutral probabilities which can be interpreted as the risk-adjusted beliefs of market participants about the stability of the exchange rate regime. Given the overall small currency premium on exchange rate risk $^{5}$ risk-neutral probabilities do not differ substantially from their statistical counterparts.

The paper is structured as follows: Section 2 contains a brief description of the model, the data and the estimation methodology. Section 3 contains the empirical results and a comparison to Jermann's findings. Section 4 summarizes the paper.

\section{Methodology, Data, and Estimation}

Option pricing model with reflecting barrier. We assume that, within an option's maturity, the market participants anticipate a decrease of the exchange rate barrier $b$ to a level below

\footnotetext{
${ }^{4} \mathrm{~A}$ similar although less general model has been used to analyze the EUR/CHF case by Hanke et al. (2015); they assume that the observed exchange rate is composed of a shadow exchange rate that would prevail without the SNB's stabilization policy plus the price of a European put option on the shadow exchange rate with a strike price equal to the EUR/CHF 1.20 floor.

${ }^{5}$ De Santis and Gérard (1998) document small risk premiums for currency risk in international capital markets. Specifically, for currencies within the European Monetary Union (EMU), De Santis et al. (2003) estimate that the introduction of the Euro is unlikely to have affected the size of currency risk premiums and therefore remain small. Moreover, Svensson (1992) shows theoretically that in target zone regimes, such as the one analyzed here, currency risk premiums are small.
} 
the EUR/CHF 1.20 floor and below the strike price $X$. For this purpose, we use a model based on a reflected geometric Brownian motion, where the assumption is that the lower barrier $b$ of the process is fully credible. This means that whenever the exchange rate touches the floor, the exchange rate only prevails for an infinitely short time period on the floor in order to avoid arbitrage opportunities that would otherwise arise (see e.g. Ingersoll Jr. (1987) on p. 270 or Bergman (1996)). Apparently, the model provides only non-zero put option prices for strike prices set above the floor level.

A stock option pricing model based on this process has been developed by Veestraeten (2008), and was corrected for put options by Hertrich and Veestraeten (2013). The model allows to estimate the implied barrier from market prices, under specific assumptions regarding the volatility of the underlying security. The original version of this model, however, does not assume a perpetual flow of dividends proportional to the level of the contemporaneous stock price, which is equivalent to a constant, continuously compounded rate of interest on the foreign currency when the underlying security is an exchange rate. The adjusted Veestraeten model for put options with $X>b$ is $\operatorname{then}^{6}$

$$
\begin{aligned}
\hat{P} \equiv & P\left(X, S_{t}, r, r^{f}, \sigma, \tau, b\right)_{t ; X>b} \\
= & X \exp ^{-r \tau} \Phi\left(-z_{1}+\sigma \sqrt{\tau}\right)-S_{t}^{*} \Phi\left(-z_{1}\right)-b \exp ^{-r \tau} \Phi\left(-z_{3}+\sigma \sqrt{\tau}\right) \\
& +S_{t}^{*} \Phi\left(-z_{3}\right)+\frac{1}{\theta}\left\{b \exp ^{-r \tau} \cdot \Phi\left(-z_{3}+\sigma \sqrt{\tau}\right)-S_{t}^{*}\left(\frac{b}{S_{t}}\right)^{1+\theta}\right. \\
& \left.\cdot\left\{\Phi\left(z_{4}\right)-\Phi\left(z_{2}\right)\right\}-X \exp ^{-r \tau}\left(\frac{X}{b}\right)^{\theta-1} \Phi\left(z_{2}-\theta \sigma \sqrt{\tau}\right)\right\}, \\
= & P(X, \cdot)-P(b, \cdot)+\frac{1}{\theta}\left\{b \exp ^{-r \tau} \Phi\left(-z_{3}+\sigma \sqrt{\tau}\right)\right. \\
& \left.-S_{t}^{*}\left(\frac{b}{S_{t}}\right)^{1+\theta}\left\{\Phi\left(z_{4}\right)-\Phi\left(z_{2}\right)\right\}-X \exp ^{-r \tau}\left(\frac{X}{b}\right)^{\theta-1} \Phi\left(z_{2}-\theta \sigma \sqrt{\tau}\right)\right\},
\end{aligned}
$$

\footnotetext{
${ }^{6}$ The detailed derivation is available in an Appendix available from the authors.
} 
with

$$
\begin{aligned}
\tau & =T-t, \\
S_{t}^{*} & =S_{t} \exp ^{-r^{f} \tau}, \\
\theta & =2 \frac{\left(r-r^{f}\right)}{\sigma^{2}}, \\
z_{1} & =\frac{\ln \left(S_{t} / X\right)+\left(r-r^{f}+\sigma^{2} / 2\right) \tau}{\sigma \sqrt{\tau}}, \\
z_{2} & =\frac{\ln \left(b^{2} /\left[S_{t} X\right]\right)+\left(r-r^{f}+\sigma^{2} / 2\right) \tau}{\sigma \sqrt{\tau}}, \\
z_{3} & =\frac{\ln \left(S_{t} / b\right)+\left(r-r^{f}+\sigma^{2} / 2\right) \tau}{\sigma \sqrt{\tau}}, \\
z_{4} & =\frac{\ln \left(b / S_{t}\right)+\left(r-r^{f}+\sigma^{2} / 2\right) \tau}{\sigma \sqrt{\tau}},
\end{aligned}
$$

where $X$ is the strike price of the option contract, $S_{t}$ is the EUR/CHF spot exchange rate (denoted in Swiss francs per Euro), and $r\left(r^{f}\right)$ are the annual continuously compounded riskfree interest rates of the domestic (foreign) currency, respectively; $\sigma$ is the constant annualized volatility of the non-reflected geometric Brownian motion; $\tau$ is the time to maturity in years, and $\Phi(\cdot)$ denotes the cumulative distribution function of the standard normal distribution. Notice that $P(X, \cdot)$ and $P(b, \cdot)$ denote the Garman-Kohlhagen $(\mathrm{GK})$ put prices $^{7}$ with strike prices $X$ and $b$, respectively:

$$
P \equiv P\left(X, S_{t}, r, r^{f}, \sigma, \tau\right)_{t}=X \exp ^{-r \tau} \Phi\left(-d_{2}\right)-S_{t} \exp ^{-r^{f} \tau} \Phi\left(-d_{1}\right)
$$

with $d_{1}=z_{1}$ and $d_{2}=d_{1}-\sigma \sqrt{\tau}$.

Data. Standardized FX options are mainly traded over-the-counter (OTC) as part of the overall foreign exchange and money market trading desk of banks. There are exchangetraded currency options in the US, but the OTC market is much more relevant for the

\footnotetext{
${ }^{7}$ The GK model is the currency option equivalent to the Black-Scholes model for stock options and relies on a standard geometric Brownian motion for the exchange rate dynamics.
} 
EUR/CHF exchange rate analyzed here. ${ }^{8}$ We retrieve the option data from Bloomberg for the time period from September 06, 2011 to January 14, 2015.

In FX option markets, it is standard to quote option prices in terms of GK-model implied volatilities for each maturity (Reiswich and Wystup, 2010). ${ }^{9}$ Moreover, the volatilities of outof-the money options are quoted on a "delta" basis; this means that they are not extracted from contracts with specific fixed strike prices (as in the case of equity options), but from contracts where the strike price is continuously reset such that a specific constant GK option delta is maintained. The idea is to keep the "moneyness" of the contracts constant over time and to make the quotes comparable. Bloomberg releases GK-implied volatilities for two deltas, $-10 \%$ and $-25 \%$. In the subsequent analysis, we will only use the $25 \Delta$ data, and contract maturities of $\tau \in\{1$ month, 3 months and 12 months $\}$, most results however relying on 3 month (3m) contracts. We use the corresponding CHF LIBOR and EUR LIBOR interest rates as risk-free interest rates.

Empirical implementation. In the empirical estimation of the model, we set the observed market prices equal to the theoretical Veestraeten prices and solve Equation (1) numerically for the implicit barrier level $b$. This apparently requires a specific assumption about the underlying volatility: We assume that investors use the previous day's implied volatility as an estimate for today's implied volatility, following Whaley (1993), Bakshi et al. (1997), among others. The high forecasting power of this procedure has recently been compared to alternative measures by, e.g., Satchell (2007) and Wang and Daigler (2011). The volatility smile effect is captured by applying the Vanna-Volga estimation procedure, thereby getting implied volatilities as of time $t$ that are consistent with the previous day's smile curve. ${ }^{10} \mathrm{We}$

\footnotetext{
${ }^{8}$ There is little information on trading volumes of OTC forex option markets. The latest available data from the BIS's Triennial Central Bank Survey in April 2013 show that the CHF is the second most actively traded currency vis-a-vis the EUR, with a share of $11 \%$.

${ }^{9}$ Details about how put and call option implied volatilities are derived from active market quotes can be found in Castagna and Mercurio (2005), among others.

${ }^{10}$ More details about the Vanna-Volga method can be found e.g. in Castagna and Mercurio (2007), Wystup (2010) and Bossens et al. (2010).
} 
approximate the volatility level $\sigma$ for the option price $\hat{P}$ with strike price $X$ in Equation (1) as of time $t$ using the previous day's price information, i.e., the strike prices $X_{1}=X_{25 \Delta P}, X_{2}=$ $X_{A T M}, X_{3}=X_{25 \Delta C}$ of the option contracts with a maturity $\tau$ of three months, the risk-free interest rates $r, r^{f}$ and the volatility levels $\sigma_{25 \Delta P}, \sigma_{A T M}$ and $\sigma_{25 \Delta C}$ as of time $t-1$. Notice that the subindices $25 \Delta P, A T M$ and $25 \Delta C$ denote put options with an option delta of $-25 \%$, at-the-money options, and call options with an option delta of $25 \%$, respectively. We apply the Vanna-Volga approximation proposed by Castagna and Mercurio (2005) in their equation (12), p. 44, and set $\sigma=\sigma_{A T M}$, for estimating the implied volatility $\sigma^{V V}$.

Based on the VV-implied volatility, the implied barrier level $b$ can be numerically computed. As the Veestraeten put pricing formula is a continuous and decreasing function in $b$, the bisection method can be applied. ${ }^{11}$

In a final step, the risk-neutral exercise probabilities for $X>b$, denoted by $\hat{\pi}$ are derived by

$$
\begin{aligned}
\hat{\pi}^{b} & =\int_{b}^{X} f\left(S_{T}, S_{t}, r, \sigma, \tau, b\right) d S_{T} \\
& =\Phi\left(-z_{1}+\sigma \sqrt{\tau}\right)-\left(\frac{X}{b}\right)^{\theta-1} \Phi\left(z_{2}-\theta \sigma \sqrt{\tau}\right),
\end{aligned}
$$

where $f\left(S_{T}\right)$ denotes the risk-neutral density function (or transition function) for a reflected geometric Brownian motion process. The first term equals the risk-neutral probability of option exercise for $X>-\infty$ in the GK model (Equation (2)). Consequently, the second term, which is negative, shows the effect of the lower reflecting barrier on the risk-neutral cumulative density function. The risk-neutral break probability $\hat{\pi}^{1.20}$ of the exchange rate dropping below the EUR/CHF 1.20 floor follows by setting $X=1.20$ in $z_{1}$ and $z_{2}$.

\footnotetext{
${ }^{11}$ For a given volatility level, we choose one price above and one price below the observed market price, and then repeatedly narrow the interval successively to find the floor level $b$ which supports the observed prices.
} 


\section{Empirical Results}

\subsection{Implied Floor $b$}

The empirical estimates for the implied floor level are displayed in Figure (1) and shows substantial variation within the range of EUR/CHF 1.10 and EUR/CHF 1.20 for most part of the observation period, with an overall positive trend up to August 2014, which implies that the credibility for maintaining the floor improved over time. The positive trend benefited, in particular, from the announcement of the unlimited bond buying program by the president of the ECB on September 6, 2012 (the "Draghi put" option) to strengthen the Euro, and from the revaluation of the Euro with respect to the Swiss franc in January 2013, when the implied floor $b$ reached levels close to the EUR/CHF 1.20 floor. The floor started to decline sharply after August 2014, which may have been related to the statements of Draghi at the Jackson Hole conference (August 22, 2014) where he alluded to implement "unconventional instruments" to raise inflationary expectations over the medium- to long-term.

\section{[Insert Figure (1) here]}

The figure also reveals another interesting episode in the period from April to September 2012: while the EUR/CHF exchange rate remained close to the EUR/CHF 1.20 floor, the implied floor shows substantial variability. It demonstrates how option markets reflect valuable information when spot markets are impeded in doing so. A substantial decrease of the floor can be observed on May 25, 2012, when the Spanish bank Bankia received a 19 billion Euro bailout, and a strong recovery of the implied floor happened after June 9, 2012, when the European community decided to grant Spain a financial support package of 100 billion Euro.

Overall, our analysis highlights the use of the modified Veestraeten model for extracting important information from market prices to gauge the changing attitude of financial market participants towards the credibility of central banks under a strong-side convertibility undertaking. As illustrated in Figure (1), the spread between the estimated lower barrier $b$ and 
the targeted floor of EUR/CHF 1.20 can be regarded as a direct market-based measure of central bank credibility, ${ }^{12}$ an approach which can be applied whenever central banks operate in target zones, even for the case of a unilateral target zone.

Notice, however, that the credibility argument is somehow flawed outside the target zone; the increased implied floor $b$ may then simply reflect the increased exchange rate (through the decrease of the put option price) without being related to the central bank's credibility. Of course, this depends on whether the fluctuation of the exchange rate is regarded as part of the bank's credibility or not. Depending on which perspective one takes, one may alternatively gauge the spread between the estimated lower barrier $b$ and the actual exchange rate $S_{t}$ as a measure of central bank credibility. These two spreads are displayed in the lower part of Figure (1).

\subsection{Implied Risk-Neutral Break Probabilities $\hat{\pi}^{1.20}$}

Based on the previous implied lower barrier estimates b, Equation (3) can be used to compute the implied risk-neutral break probabilities $\hat{\pi}^{1.20}$, which are displayed in Figure (2):

$$
\text { [Insert Figure (2) here] }
$$

The solid line represents the probabilities implied by the $3 \mathrm{~m}$-contracts. Not surprisingly, the introduction of the floor in September 2011 helped the Euro to gain credibility vis-a-vis the Swiss franc: the break probabilities decreased from 50\% to below $40 \%$ towards the end of that year, but increased again to $50 \%$ towards the second quarter of 2012. It was not until September 2012 (in the aftermath of the announcement of the "Draghi put") that the market perceived the SNB's ability to defend the floor as more credible. It is interesting to notice that the sharp drop of the probability did not occur at the first announcement of Draghi's plans in London on July 27, 2012, but only after the details of the program were announced on September 6. This observation underpins the credibility and reputation of the ECB has

\footnotetext{
${ }^{12}$ Similarly, Rangvid and Sørensen (2001) use the difference between their shadow exchange rate and the market rate for measuring the currency misalignment or the credibility of a target zone.
} 
as a key player in the financial system. As a consequence, the risk-neutral break probabilities decreased sharply to some $35 \%$. In January 2013, the revaluation of the Euro lowered the break probabilities substantially, but the time period up to August 2014 was characterized by huge fluctuations between zero and 30\%. Occasionally, the probability decreased to zero (end of May, mid-October, end of November 2013, and in early January 2014). The situation changed drastically in August 2014 when the break probability jumped to 40\%, and even further up to $50 \%$ between October and November; it remained at that level until the floor was abandoned by the SNB on January 14, 2015.

In Figure (2), we also add our estimates from $1 \mathrm{~m}$ - and $12 \mathrm{~m}$-contracts. The spread between the probabilities varies substantially over time. Interestingly, even in time periods of high credibility, when the $1 \mathrm{~m}$-probability is essentially zero, does the $12 \mathrm{~m}$-estimate not fall much below $30 \%$. Towards the end of the regime, the probabilities are very close together.

Overall, while the credibility of the exchange rate floor increased shortly after its introduction and between early 2013 and mid 2014, the break probability of the floor remained above $10 \%$ over most of the time period and was therefore far from negligible. The credibility particularly worsened after Draghi's speech at the Jackson Hole conference in late August 2014 and remained at levels around 50\%. Accordingly, our results in Figure (2) indicate that the SNB's credibility to enforce the floor was far from perfect as seen from the currency options market perspective. ${ }^{13}$ When the SNB abandoned the floor on January 15, 2015, this came as a big surprise for the public and most market commentaries. But the information from the option market, at least since mid-November of the preceding year, told a different story: Our model implies that the observed option prices indicated a realignment of the floor to approximately EUR/CHF 1.15 with a $50 \%$ chance within the next few months - not a complete abandonment of the floor, however, as it actually happened.

\footnotetext{
${ }^{13}$ According to Bekaert and Gray (1998), an exchange rate target zone is only perfectly credible, if there is zero probability of observing an exchange rate outside the target zone.
} 


\subsection{A Comparison to Jermann's results}

The empirical findings of Jermann (2015) imply quarterly break probabilities in the range of 5\%-35\% (with only very few cases at 50\%), and a shadow exchange rate between EUR/CHF 1.03 and EUR/CHF 1.22. In general, our estimates imply higher break probabilities, especially in periods when fears of a break-up of the Eurozone emerged (e.g. in spring 2012) or when the Eurozone debt crisis escalated (e.g. in summer 2012) before Draghi's "put option" calmed down markets - a period where the observed EUR/CHF exchange rate was close to the floor. We find that in this period the credibility was rather low, whereas Jermann finds that the probability of the SNB to maintain the floor was rather high. Similarly, since October 2014 our model indicates a substantial increase in the probability of a realignment of the floor up to $50 \%$, whereas Jermann's model even indicates a decrease in the break probability (increase in the continuation probability) after October 2014 with estimates within a range of $10 \%$ to $20 \%$. However, notice that the results cannot be directly compared, because Jermann's model assumes that the floor is fully removed, while we assume that the floor is reset to a lower, fully credible level. As a consequence, our implied floor has not the same interpretation as his shadow exchange rate as well.

Moreover, notice that Jermann's interpretation of high credibility from April 2012 through September 2012 is at odds with the large spread he observes between the effective and the shadow exchange rate during these months. ${ }^{14}$

\section{Conclusion}

The findings of this paper suggest that the credibility of the EUR/CHF floor was far from being perfect on the side of the market participants for most of the time where the floor was in place. While the estimated break-probabilities and implied floor levels reveal a general increase in credibility in the aftermath of the announcement of Draghi's "put option" in

\footnotetext{
${ }^{14}$ This spread has been previously used in the literature (see e.g. Rangvid and Sørensen (2001)) as an indicator of the credibility of a target zone.
} 
September 2012, and improved furthermore in January 2013, the implied floor levels stayed away from EUR/CHF 1.20 for most of the time and the break probabilities reveal substantial variation between zero and 15\% even in the time-period between May 2013 and January 2014 when the credibility was highest. The picture changed substantially after August 2014 when the option market indicated a drop of the floor to EUR/CHF 1.15 with a break-probability of almost $50 \%$. This observation is in sharp contrast to the fact the the abandonment of the floor on January 15, 2015, came as a "big surprise" for most observers.

Whether our findings result from a mechanical hedging behavior of, for example, institutional investors or by active currency speculation of hedge funds and other entities, remains open. Although CFTC's commitment of traders reports (COT) separately reports commercial and non-commercial open position for currency futures and options traded in the US, this data is of little value for addressing this question: It does not separately report option positions; the data does not include OTC option trades; and it does not address currencies beyond the USD.

In general, our findings are relevant for monetary authorities. Back in the 1970s and early 1980s, the introduction of currency option trading was originally discussed among (European) central banks from the perspective of enhancing the informativeness of the foreign exchange market, and to be more specific, as a means to visualize the exchange rate uncertainty anticipated by the market participants. Interestingly, no case is known where monetary policy was explicitly tied to information extracted from option prices, although the benefits are occasionally discussed (Breuer, 1999). Our results show that the market prices of liquid option contracts, in connection with an option pricing model, convey important information about a central bank's ability to enforce credible policy actions. At least, market based information should be contrasted with official statements by authorities or public commentaries, which are often over-confident compared to the financial market's opinion, as it was the case in the EUR/CHF episode analyzed here. 


\section{References}

Bakshi, G., Cao, C., Chen, Z., 1997. Empirical Performance of Alternative Option Pricing Models. Journal of Finance 52 (5), 2003-2049.

Bekaert, G., Gray, S. F., 1998. Target Zones and Exchange Rates: An Empirical Investigation. Journal of International Economics 45 (1), 1-35.

Bergman, Y. Z., 1996. Equilibrium Asset Price Ranges. International Review of Financial Analysis 5 (3), 161-169.

Bernholz, P., 2015. The Swiss Experiment: From the Lower Bound to Flexible Exchange Rates. Cato Journal 35 (2), 403-410.

Bossens, F., Rayée, G., Skantzos, N., Deelstra, G., 2010. Vanna-Volga Methods Applied to FX Derivatives: From Theory to Market Practice. International Journal of Theoretical and Applied Finance 13 (8), 1293-1324.

Breuer, P., 1999. Central Bank Participation In Currency Option Markets. IMF Working Paper 140 (99), 1-40.

Castagna, A., Mercurio, F., 2005. Consistent Pricing of FX Options. Internal Report, Banca IMI.

Castagna, A., Mercurio, F., 2007. The Vanna-Volga Method for Implied Volatilities. Risk Magazine, 39-44.

De Santis, G., Gérard, B., 1998. How Big is the Premium for Currency Risk? Journal of Financial Economics 49 (3), 375-412.

De Santis, G., Gérard, B., Hillion, P., 2003. The Relevance of Currency Risk in the EMU. Journal of Economics and Business 55 (5), 427-462.

Gerber, H., Pafumi, G., 2000. Pricing Dynamic Investment Fund Protection. North American Actuarial Journal 4 (2), 28-37; Discussion 37-41.

Hanke, M., Poulsen, R., Weissensteiner, A., 2015. Where Would the EUR/CHF Exchange Rate be Without the SNB's Minimum Exchange Rate Policy? Working Paper, forthcoming in the Journal of Futures Markets.

Hertrich, M., Veestraeten, D., 2013. Valuing Stock Options when Prices are Subject to a Lower Boundary: A Correction. Journal of Futures Markets 33 (9), 889-890. 
Ingersoll Jr., J. E., 1987. Theory of Financial Decision Making. Totowa: Rowman \& Littlefield.

Jermann, U. J., 2015. Financial Markets' Views about the Euro-Swiss Franc Floor. Working Paper, available at SSRN 2490086.

Ko, B., Shiu, E., Wei, L., 2010. Pricing Maturity Guarantee with Dynamic Withdrawal Benefit. Insurance: Mathematics and Economics 47 (2), 216-223.

Rangvid, J., Sørensen, C., 2001. Determinants of the Implied Shadow Exchange Rates from a Target Zone. European Economic Review 45 (9), 1665-1696.

Reiswich, D., Wystup, U., 2010. A Guide to FX Options Quoting Conventions. Journal of Derivatives 18 (2), 58-68.

Satchell, S., 2007. Forecasting Expected Returns in the Financial Markets. London: Academic Press.

Svensson, L. E. O., 1992. The Foreign Exchange Premium in a Target Zone Model with Devaluation Risk. Journal of International Economics 33 (1), 21-40.

Veestraeten, D., 2008. Valuing Stock Options when Prices are Subject to a Lower Boundary. Journal of Futures Markets 28 (3), 231-247.

Wang, Z., Daigler, R., 2011. The Performance of VIX Option Pricing Models: Empirical Evidence Beyond Simulation. Journal of Futures Markets 31 (3), 251-281.

Whaley, R., 1993. Derivatives on Market Volatility: Hedging Tools Long Overdue. Journal of Derivatives 1 (1), 71-84.

Wystup, U., 2010. Vanna-Volga Pricing. In: Cont, R. (Ed.), Encyclopedia of Quantitative Finance. Vol. 4. Chichester: John Wiley \& Sons, pp. 1867-1874. 
Figure 1: Implied EUR/CHF Exchange Rate Barrier based on the Modified Veestraeten Model and the Vanna-Volga Implied Volatility and the Deviation of the EUR/CHF FX Rate and the 1.20-Floor from the Implied EUR/CHF Exchange Rate Barrier

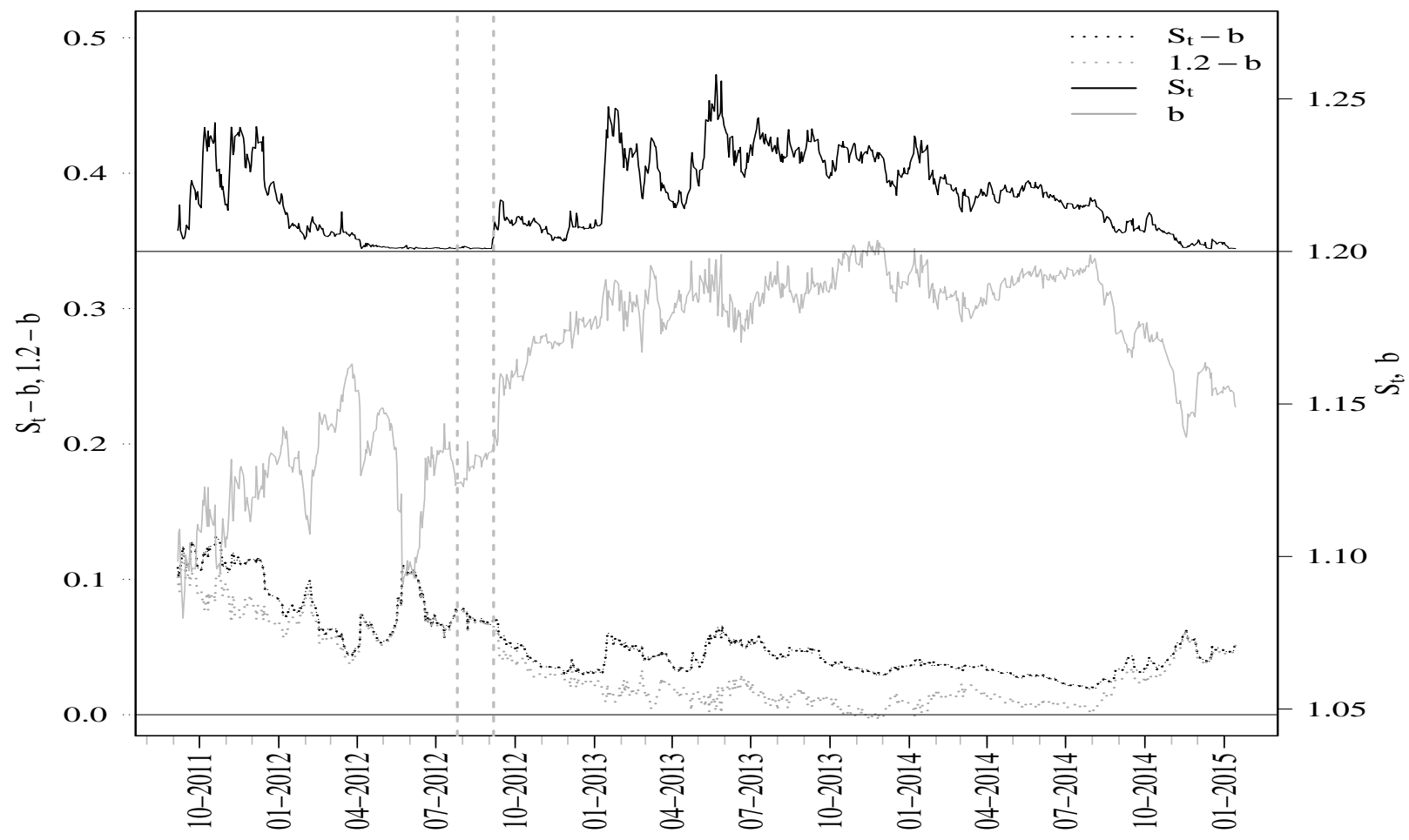

Notes: The figure shows the spot EUR/CHF exchange rate $S_{t}$ (right axis), the estimated lower barrier $b$ (right axis) assuming a 1-day lagged Vanna-Volga implied volatility level $\sigma^{V V}$ for EUR/CHF 3 -month 25-delta put options and the deviation of the EUR/CHF FX rate $S_{t}$ from the implied floor $b$ (left axis) and of the EUR/CHF 1.20 floor from the implied floor $b$ (left axis), respectively, from September 06, 2011 to January 14, 2015. The computations are based on the modified Veestraeten pricing model, as described in the text. Data source: Bloomberg, Datastream. 
Figure 2: Risk-Neutral Break Probabilities based on the Modified Veestraeten Model and the Vanna-Volga Implied Volatility

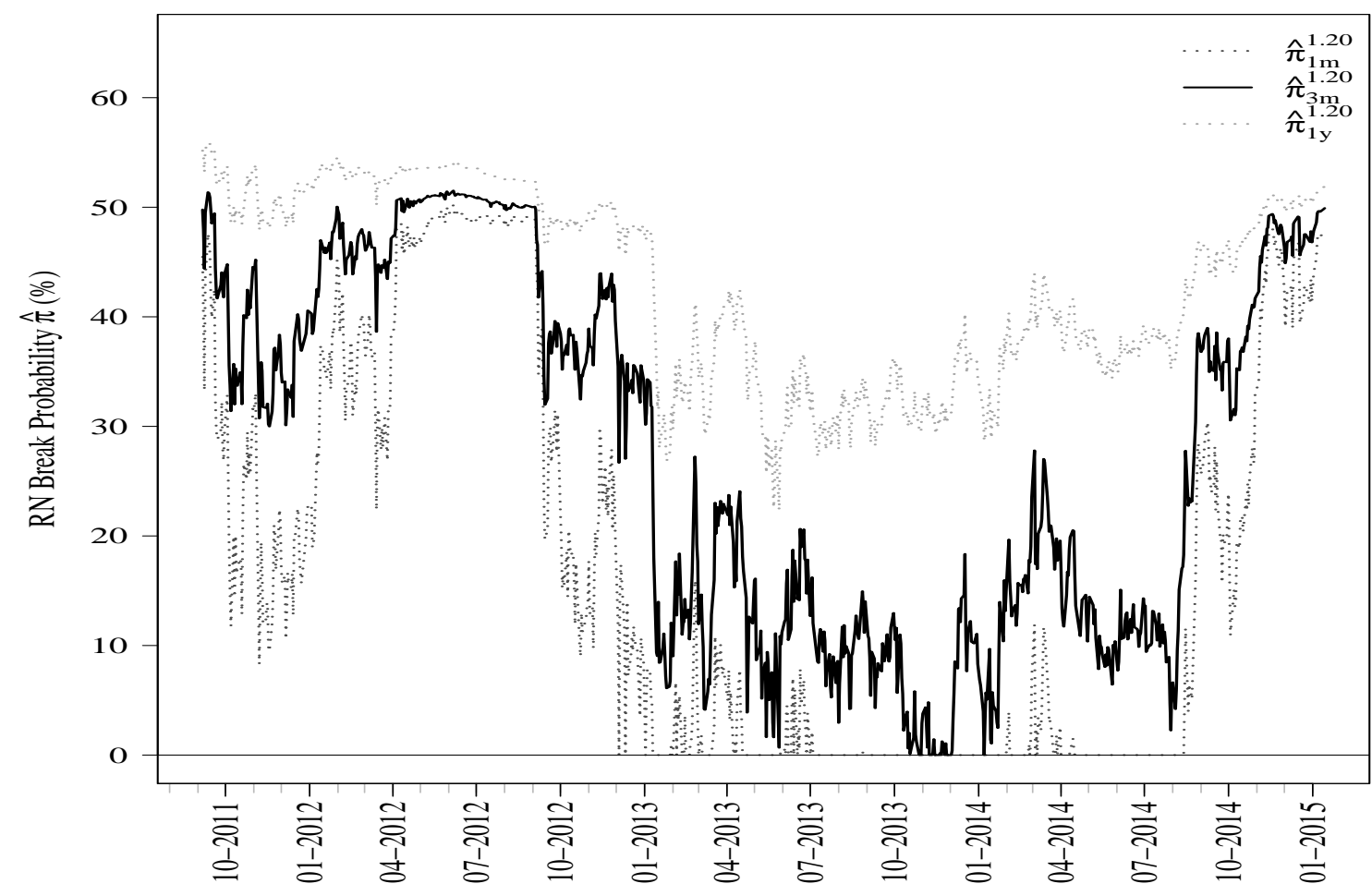

Notes: The figure shows the estimated risk-neutral break probabilities $\hat{\pi}^{1.20}$ for EUR/CHF 1-month, 3-month and 1-year 25-delta put options and the 1-day lagged Vanna-Volga implied volatilities $\sigma^{V V}$, from September 06, 2011 to January 14, 2015. To distinguish the different break probabilities according to the option contract's time to maturity $\tau$, these probabilities are denoted by $\hat{\pi}_{\tau}^{1.20}$. The computations are based on the modified Veestraeten pricing model, as described in the text. Data source: Bloomberg, Datastream. 